\title{
Isolation and characterisation of a 17-kDa staphylococcal heparin-binding protein with broad specificity
}

\author{
CORINA FALLGREN, MEEME UTT and ÅSA LJUNGH
}

Department of Infectious Diseases and Medical Microbiology, University of Lund, Sölvegatan 23, S-223 62 Lund, Sweden

\begin{abstract}
A previous study reported the ability of staphylococci to bind heparin and heparindependent host growth factors. The present study isolated and identified heparin- and basic fibroblast growth factor (bFGF)-binding surface components of $S$. epidermidis strain RP12 and $S$. haemolyticus strain SM 131. The staphylococcal heparin-binding component(s) were purified by affinity chromatography on heparin-Sepharose and a major heparin-binding protein, here designated HBP, was identified by immunoblot in these two coagulase-negative staphylococcal (CNS) species. The HBP was shown to be acidic with an approximate $\mathrm{pI}$ of 4.6 and a molecular mass around $17 \mathrm{kDa}$. The binding of heparin to HBP was inhibited by heparin, fucoidan, pentosan polysulphate and various other sulphated polysaccharides, but not by non-sulphated compounds. However, the purified HBP from both $S$. epidermidis and $S$. haemolyticus revealed broad specificity, and also bound bFGF, thrombospondin, von Willebrand factor and, weakly, fibrinogen. The N-terminal sequences of the 17-kDa HBP from $S$. epidermidis and $S$. haemolyticus showed only limited identity. Comparison of the first 15 amino acid residues derived from either strain with known sequences in the protein databases revealed no close similarities. Taken together, these results suggest that the adhesion of at least some CNS to host sulphated glycosaminoglycans may be mediated by a previously uncharacterised group of surface proteins.
\end{abstract}

\section{Introduction}

Staphylococcus aureus is primarily a human pathogen, causing a broad spectrum of diseases ranging from septicaemia to localised skin infections. Both $S$. aureus and coagulase-negative staphylococci (CNS) form part of the normal skin microflora. CNS strains were formerly regarded as opportunist pathogens, inducing systemic infections in immunocompromised patients [1]. However, CNS cause more infections of medical devices than any other group of micro-organisms and have emerged as the most frequently isolated pathogens of nosocomial sepsis $[1,2]$. They may also give rise to endocarditis, endophthalmitis, osteomyelitis and urinary tract infections.

Several virulence factors have been identified in $S$. aureus $[3,4]$ including different toxins and haemoly-

Received 29 Aug. 2000; revised version received 20 Nov. 2000; accepted 4 Dec. 2000.

Corresponding author: Dr A. Ljungh (e-mail: asa. ljungh@mmb.lu.se). sins, tissue-degrading enzymes, coagulase and fibrinogen-binding proteins, and several surface proteins which mediate adhesion to extracellular matrix (ECM) proteins such as fibronectin (Fn), vitronectin $(\mathrm{Vn})$, collagen $(\mathrm{Cn})$, thrombospondin (TSP), laminin and plasminogen [5].

Current concepts on the pathogenesis of wound and biomaterial-associated infections caused by CNS have focused on various interactions between staphylococci and host ECM proteins or serum components [6]. An earlier study showed that CNS strains bind ECM proteins in immobilised rather than soluble form and often bind immobilised proteins at higher levels than $S$. aureus [5]. This may be particularly relevant in biomaterial-associated infections, as host proteins immediately adsorb to the biomaterial surface and are thus present in immobilised forms [6].

Two surface proteins of $S$. aureus with mol. wts of 66 and $60 \mathrm{kDa}$, respectively, were earlier identified as binding heparan sulphate (HS) and heparin [7]. Also, CNS may interact with heparin and HS, as shown for 
whole staphylococcal cells which bound avidly to heparinised polymer surfaces [8], or to heparin immobilised on latex particles [9]. The ability of both $S$. aureus and CNS strains to bind the heparin-binding growth factors, basic fibroblast growth factor (bFGF) and platelet-derived growth factor (PDGF) has also been shown [10].

Heparin and HS constitute a class of glycosaminoglycans (GAGs) with common structural features [11]. The polysaccharide chains in heparin and HS proteoglycans are composed of partially sulphated, alternating hexuronic (L-iduronic or D-glucuronic) acid and Dglucosamine (N-sulphated or $\mathrm{N}$-acetylated) residues. They differ as follows: heparin is highly sulphated and rich in L-iduronic acid, whereas HS is less sulphated and is rich in D-glucuronic acid. HS is located on the surface of most eukaryotic cells and forms part of the ECM [12], whereas heparin is stored intracellularly, mainly in mast cells, and is released upon external signalling. By binding to antithrombin III, which interacts with thrombin, heparin exerts an anticoagulative effect. However, the anticoagulant activity of HS is much lower than that of heparin [13]. Interestingly, a number of growth factors require binding to heparin and cell surface HS upon their activation during tissue repair. During wound healing in human skin, a correlation between expression of basement membrane HS and normal epidermal proliferation was observed [14].

This report describes the isolation of a $17-\mathrm{kDa}$ heparinbinding surface protein from CNS.

\section{Materials and methods}

\section{Chemicals}

Heparin (mol. wt 4000-6000) was purchased from Fluka (Heidelberg, Germany). A Heparin-HiTrap, column $(5 \mathrm{ml})$ was obtained from Pharmacia Biotech, Uppsala, Sweden. Thrombospondin (TSP) and von Willebrand Factor (vWF) were gifts from Professors J. Lawler and F. Dorner, respectively. Rabbit anti-human TSP, vWF, Fg, Fn and Vn, and peroxidase (HRP)conjugated goat anti-mouse IgG and HRP-swine antirabbit IgG were purchased from Dako (Glostrup, Denmark). Amino-carbazole, 5([4,6-dichlorotriazin2yl]amino) fluorescein (DTAF), basic fibroblast growth factor (bFGF) human recombinant, chondroitin 4sulphate, monoclonal anti-bFGF antibody, long-arm biotin-hydrazide, bovine serum albumin, cholera toxin, dextran sulphate (mol. wt 8000), fucoidan, hyaluronic acid from bovine trachea, pentosan polysulphate, sodium acetate, sodium periodate, HRP-conjugated streptavidin and toluidine blue were obtained from

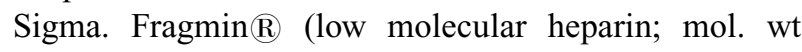
5000) was purchased from Kabi AB (Stockholm, Sweden). Suramin (Germanin $(\mathbb{R})$ was from Bayer AG (Leverkusen, Germany) and Tween 20 from Merck AG
(Darmstadt, Germany). Blood Agar (BA) base was purchased from Lab M (Salford) and supplemented with horse erythrocytes 4\%. Tryptic Soy Broth (TS) was from Difco Laboratories (Detroit, MI, USA). All buffers and chemicals were of analytical grade.

\section{Bacterial strains and growth conditions}

S. aureus strain V8, S. epidermidis strain RP 12, S. haemolyticus strain SM 131 and other strains of different CNS species, isolated from patients with osteomyelitis and biomaterial-associated infections (n $=40)$ were studied [5]. S. saprophyticus strain TW 111 , isolated from a patient with urinary tract infection and previously shown by agglutination assay [9] not to bind heparin was included as a negative control. CNS strains isolated from healthy carriers were also included. The test strains were cultured on BA at $37^{\circ} \mathrm{C}$ for $20-22 \mathrm{~h}$. Bacterial cells were harvested in the late stationary phase by centrifugation $(1760 \mathrm{~g}$ for $20 \mathrm{~min}$ ), washed twice with PBS, pH 7.2, and suspended in PBS at a final concentration of $10^{9} \mathrm{cfu} / \mathrm{ml}$.

\section{Biotinylation of staphylococci}

Equal volumes of bacteria and biotin (EZ-Link-SulfoNHS-LC-biotin, Boule Nordic AB Stockholm, Sweden) solution $(0.2 \mathrm{mg} / \mathrm{ml}$ in $\mathrm{PBS}, \mathrm{pH} 7.6)$ were incubated for $2 \mathrm{~h}$ at ambient temperature. The staphylococcal cells were then washed three times with PBS and resuspended at the original concentration in PBS containing bovine serum albumin (BSA) 1\%.

\section{Cell surface extracts}

For extraction of cell-surface components, cells of strain S. epidermidis RP 12, S. haemolyticus SM 131 and $S$. aureus V8 were washed twice in PBS, resuspended in $2.5 \mathrm{ml}$ of $1.0 \mathrm{M} \mathrm{LiCl}$, supplemented with protease inhibitors (Complete ${ }^{\mathrm{TM}}$ Mini, Boehringer Mannheim, Germany) and incubated for $2 \mathrm{~h}$ at $37^{\circ} \mathrm{C}$ with agitation [7]. After centrifugation $(8827 \mathrm{~g}, 30$ min) the supernates were dialysed against PBS for $2 \mathrm{~h}$ at $4{ }^{\circ} \mathrm{C}$. The protein content was determined by a BioRad microassay (BioRad, Richmond, CA, USA), with BSA as a standard. The crude $\mathrm{LiCl}$ extracts were stored at $-20^{\circ} \mathrm{C}$.

\section{Preparation of ${ }^{125} 1$-DTAF-heparin and biotinylated heparin}

To enable iodine labelling, DTAF was conjugated to heparin as described previously [15]. DTAF-heparin was dissolved in PBS at a concentration of $1-2 \mathrm{mg} / \mathrm{ml}$. The pellet was lyophilised and stored dry at $4^{\circ} \mathrm{C}$. DTAF-heparin was iodinated with $\mathrm{Na}^{125} \mathrm{I}$ (Radiochemical Centre, Amersham) and Iodo-beads (Pierce Chemical Company, Rockford, IL, USA) according to the method of Pascu et al. [10]. Heparin was 
biotinylated as described by Utt and Wadström [16]. Biotinylated heparin was dissolved in water $(1 \mathrm{mg} / \mathrm{ml})$ and used as a stock solution.

\section{Immobilised GAG-binding assay}

Nunc-Maxisorp 96-well microtitration plates were covalently coupled with heparin, chondroitin 4-sulphate and dextran sulphate by end-point attachment (EPA) [17]. The presence of GAGs on the microtitration plates was detected by a chromatic method with toluidine blue stain [17]. Briefly, a positive chromatic reaction was detected when the well coated with GAGs was stained violet compared with the colour of uncoated wells which remained uncoloured. The plates were blocked overnight at $4{ }^{\circ} \mathrm{C}$ with BSA $(400 \mu \mathrm{l}$ of a $1 \%$ solution in PBS). Finally, the biotinylated bacterial suspension $\left(100 \mu \mathrm{l}\right.$ containing $\left.5 \times 10^{8} \mathrm{cfu} / \mathrm{ml}\right)$ was added. The plates were incubated on a platform shaker for $2 \mathrm{~h}$ at ambient temperature. Unbound bacteria were removed by washing three times with PBS containing Tween $200.05 \%$ (PBST). HRP-labelled NeutrAvidin ${ }^{\mathrm{TM}}$ (Boule Nordic AB) $(100 \mu \mathrm{l}$ of a 1 in 1500 dilution in PBS containing BSA $1 \%$ ) was added to each well and incubated for $1 \mathrm{~h}$ at $37^{\circ} \mathrm{C}$. The plates were washed three times with PBS, and $100 \mu \mathrm{l}$ of ImmunoPure TMB substrate kit (Boule Nordic AB) were added to each well. The colour was allowed to develop for $5 \mathrm{~min}$ and the absorbance at $450 \mathrm{~nm}$ was measured with a microtitration plate reader (Multiscan, ELISA Reader). The controls used in the ELISA assay were: the heparincoated wells containing all ingredients except biotinylated bacteria and the heparin-coated wells incubated only with ImmunoPure TMB substrate kit. The $\mathrm{OD}_{450}$ values for the controls (background) were 0.270 (SD 0.010 ) and 0.105 (SD 0.015), respectively. All assays were performed twice and the means and SD were calculated.

\section{Isolation of heparin-binding proteins}

The crude $\mathrm{LiCl}$ extracts $(5-6 \mathrm{ml})$ of $S$. epidermidis RP 12, S. haemolyticus SM 131 and S. aureus V8 were applied to a Heparin-HiTrap column equilibrated with PBS containing Tween $200.1 \%, \mathrm{pH}$ 7.2. Material retained by the column was eluted at a flow rate of $1 \mathrm{ml} / \mathrm{min}$ with a linear $0-2 \mathrm{M} \mathrm{NaCl}$ gradient in the same buffer. The peak fractions at $280-\mathrm{nm}$ absorbance were pooled, dialysed against water (overnight at $4{ }^{\circ} \mathrm{C}$ ), run on SDS-PAGE and silver stained (silver stain kit from BioRad).

\section{SDS-PAGE, immunoblotting and autoradiography}

S. epidermidis RP 12, S. haemolyticus SM 131 and S. aureus V8 cell-surface proteins ( $\mathrm{LiCl}$ crude preparations or purified fractions) were separated and analysed by SDS-PAGE under reducing conditions in Miniprotean II or Protean II cell slab gel vertical electrophoresis equipment (BioRad) with 12\% separating gels or gradient gels $(4-15 \%)$. Proteins were transferred to Immobilon $\mathbb{R}$ polyvinylidone difluoride membrane (PVDF) (Millipore Intertech, Bedford, MA, USA) by electrotransfer and the membrane was blocked with buffer I for 15 min [18]. Strips of the membrane were incubated with biotinylated heparin or with ${ }^{125}$ I-DTAF-heparin $\left(3 \times 10^{5} \mathrm{cpm} / \mathrm{ml}\right)$ diluted in a washing buffer composed of PBS containing BSA $1 \%$ and Tween $200.1 \%$, overnight at $20^{\circ} \mathrm{C}$. The strips probed with biotinylated heparin were then rinsed three times for $5 \mathrm{~min}$ in washing buffer and incubated for $2 \mathrm{~h}$ at $20^{\circ} \mathrm{C}$ with streptavidin-HRP (diluted 1 in 3000 in washing buffer) [18]. The controls used in immunoblot assays were the strips incubated only with streptavidinHRP, except biotinylated heparin. After washing as above the strips were incubated with $50 \mathrm{mM}$ sodium acetate buffer containing 3-amino-9-ethyl carbazole $0.04 \%$ and $\mathrm{H}_{2} \mathrm{O}_{2} \quad 0.015 \%$. The blots probed with ${ }^{125} \mathrm{I}-$ DTAF-heparin were dried and examined by autoradiography $\left(-70^{\circ} \mathrm{C}, \quad\right.$ c. $\left.48 \mathrm{~h}\right)$ with $\mathrm{X}$-Omat $\mathrm{AR}$ film (Eastman, Kodak). The specificity of HBP binding [19] was tested by pre-incubation of the strips with a mixture of heparin or other polysulphated agents $(100 \mu \mathrm{g} / \mathrm{ml}$ final concentration) and biotinylated heparin or bFGF.

To ensure that the HBP is a surface protein, bacterial cells were biotinylated before $\mathrm{LiCl}$ extraction and the proteins were resolved by SDS-PAGE and Western blotted with streptavidin peroxidase. $\mathrm{LiCl}$ extract from non-biotinylated bacterial cells probed with heparinbiotin was used as a positive control.

\section{bFGF immunoblot binding assay}

Binding assays with bFGF were performed in PBS containing BSA $1 \%$ and Tween $200.1 \%$ at pH 5 and 6. PVDF strips containing HBP were incubated with bFGF $50 \mathrm{ng} / \mathrm{ml}$ overnight at $20^{\circ} \mathrm{C}$. The strips were then rinsed three times for $5 \mathrm{~min}$ in washing buffer and incubated for $2 \mathrm{~h}$ at $20^{\circ} \mathrm{C}$ with mouse anti-bFGF immunoglobulins. The strips were rinsed as above and incubated with peroxidase-conjugated goat antimouse immunoglobulins (diluted 1 in 1000) for $1 \mathrm{~h}$ at $20^{\circ} \mathrm{C}$. As controls, strips containing HBP incubated only with primary and secondary antibody, except bFGF, were used. After washing as above, the strips were incubated with $50 \mathrm{mM}$ sodium acetate buffer containing 3-amino-9-ethylcarbazole $0.04 \%$ and $\mathrm{H}_{2} \mathrm{O}_{2}$ $0.015 \%$.

\section{Amino-terminal amino acid sequence}

Samples of purified heparin-binding proteins from $S$. haemolyticus SM 131 and S. epidermidis RP 12 were transferred to PVDF membranes after SDS-PAGE. These membranes were stained with Coomassie Brilliant Blue R-250 $0.1 \% \mathrm{w} / \mathrm{v}$ in methanol $50 \%$ for $5 \mathrm{~min}$ and destained in methanol $50 \%$ and acetic acid $10 \%$. Protein bands were cut from the dried PVDF 
membranes, and the amino-terminal amino acid sequence was analysed in a peptide sequencer $\mathrm{ABI}$ 476A (Foster City, CA, USA).

\section{Iso-electric focusing and two-dimensional electrophoresis}

Linear precast Immobilone DryStrips, pH 3-10 $(110 \times 3 \times 0.5 \mathrm{~mm})$ from Amersham Pharmacia Biotech (Uppsala, Sweden), were rehydrated according to the manufacturer's instructions. The crude $\mathrm{LiCl}$ extracts of S. epidermidis RP 12 (50 $\mu \mathrm{g}$ of protein/strip) were loaded into a sample cup at the cathodic (basic) end of the gel strip submerged in Plusone (Drystrip cover fluid from Amersham Pharmacia Biotech). Iso-electric focusing (IEF) was performed with a programmed voltage gradient for $21 \mathrm{~h}$ to a total of $34 \mathrm{kVh}$ with horizontal electrofocusing apparatus (Multiphor II, Amersham Pharmacia Biotech). After IEF the strips were stored at $-20^{\circ} \mathrm{C}$ until required for the second dimension. After equilibration of the strips according to the manufacturer's instructions, the second dimension was performed on SDS polyacrylamide $8-18 \%$ gradient slab gels, at a constant voltage of $80 \mathrm{~V}$ for $16 \mathrm{~h}$, with Protean II vertical electrophoresis equipment and Laemmli buffer system [19]. Molecular markers in the range $14-94 \mathrm{kDa}$ were used (Amersham Pharmacia Biotech). The completed two-dimensional gels were either silver stained or transferred to PVDF membranes for further immunoblot assay, as described above.

\section{Binding of TSP and $v W F$ by HBP}

Wells in a microtitration plate (Nunc MaxiSorp) were coated overnight at $4^{\circ} \mathrm{C}$ with $100 \mu \mathrm{l}$ of a $5 \mu \mathrm{g} / \mathrm{ml}$ solution of HBP (S. epidermidis RP 12). The wells were then blocked by incubation with BSA $3 \%$ for $1 \mathrm{~h}$ at $37^{\circ} \mathrm{C}$. TSP, vWF, Fg, Fn or $\mathrm{Vn}(0.1 \mu \mathrm{g}$ of protein in $100 \mu \mathrm{l})$ were added to the wells followed by incubation for $2 \mathrm{~h}$ at room temperature. Bound serum proteins were detected by HRP-conjugated rabbit immunoglobulins against TSP, vWF, Fg, Fn or Vn diluted 1 in 1000 in PBST. The plate was washed with PBST after each incubation, developed with ImmunoPure TMB substrate and the colour was read at $450 \mathrm{~nm}$. The controls used in capture ELISA assay comprised the coated wells containing all ingredients except the tested proteins and the coated wells incubated only with ImmunoPure $\mathrm{TMB}$ substrate kit. The $\mathrm{OD}_{450}$ values for the controls (background) were 0.348 (SD 0.012) and 0.131 (SD 0.015), respectively. All assays were performed twice and the means and SD were calculated.

\section{Results}

\section{GAG-binding assay}

Binding of immobilised GAGs was common among CNS strains isolated from both biomaterial-associated infections and from healthy individuals. S. epidermidis
RP 12 and S. haemolyticus SM 131 were selected for characterisation of heparin-binding components in CNS strains (Fig. 1). The binding of heparin was optimal when staphylococci were cultured on BA. Maximal binding was obtained within $30 \mathrm{~min}$; it was most pronounced at $\mathrm{pH} 5$ and was reduced by high ionic strength (data not shown).

\section{Isolation of heparin-binding surface proteins: SDS-PAGE and immunoblot assays}

The HPLC profile revealed three ( $S$. epidermidis RP 12 ) and four ( $S$. haemolyticus SM 131) major peaks that were eluted at concentrations of $0.5,0.8,1.0$ and $1.4 \mathrm{M} \mathrm{NaCl}$. The peak materials were subjected to SDSPAGE and, for $S$. epidermidis RP 12 and $S$. haemolyticus SM 131, four-to-five bands, respectively, were detected after silver staining (three-to-five weak bands in the high mol. wt range, $60-85 \mathrm{kDa}$ ) and one strong band of $c .17 \mathrm{kDa}$ (Fig. $2 \mathrm{a}$ and b). $\mathrm{A} \mathrm{NaCl}$ concentration of $1.4 \mathrm{M}$ was needed for the elution of this protein from the heparin column, thus demonstrating the binding to be of high affinity. This band was also detected in $S$. aureus V8, but was weaker than the $60-$ and $66-\mathrm{kDa}$ HS-binding proteins reported previously (Fig. 2c) [7]. In corresponding Western blots, several proteins were found to bind heparin, one with a molecular mass of $c$. $17 \mathrm{kDa}$ being most prominent. This component was designated HBP (heparin-binding protein). Four other proteins bound to a lesser extent.

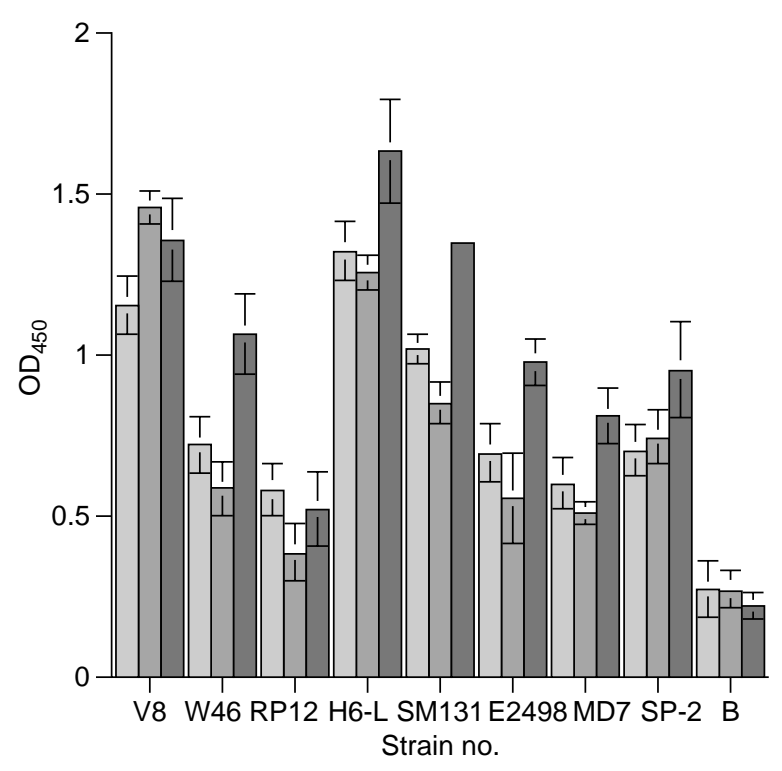

Fig. 1. Binding of staphylococcal strains to GAGs: EPAimmobilised heparin, dextran sulphate and chondroitin 4sulphate. Biotinylated staphylococcal cells were added to GAG-coated wells and allowed to adhere for $2 \mathrm{~h}$. After removal of non-adherent bacteria, bound bacteria were detected with NeutrAvidin ${ }^{\mathrm{TM}}$. Absorbance was recorded in a Multiscan ELISA reader at $450 \mathrm{~nm}$. The results are the mean value of four readings. Each batch of assays also included one or more control strains as well as blank wells (B). 
a

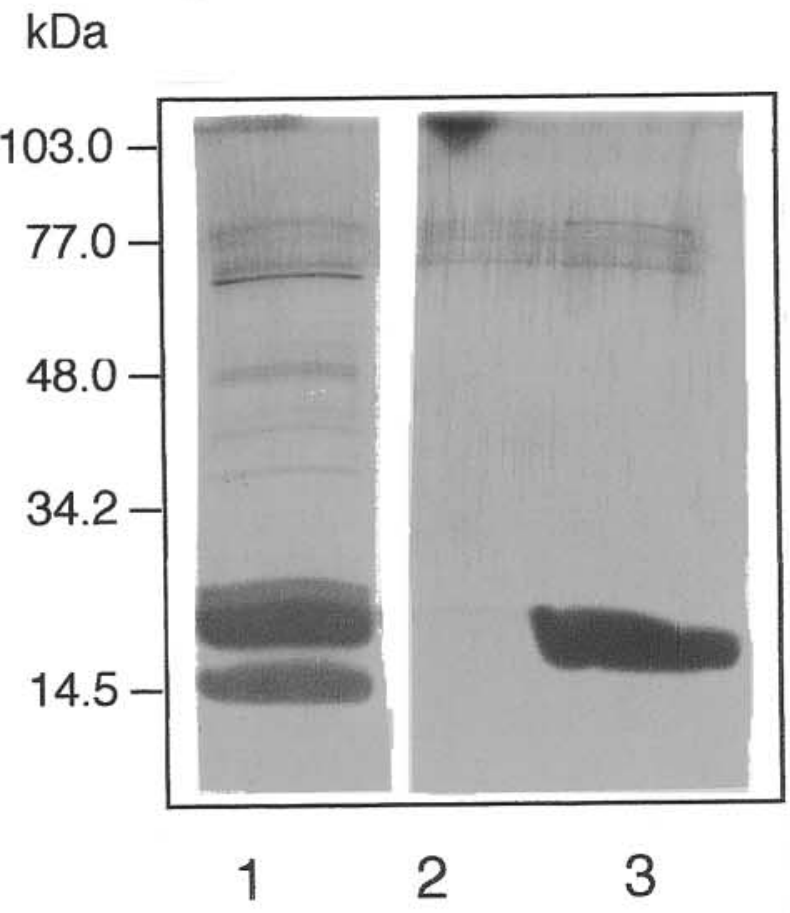

b

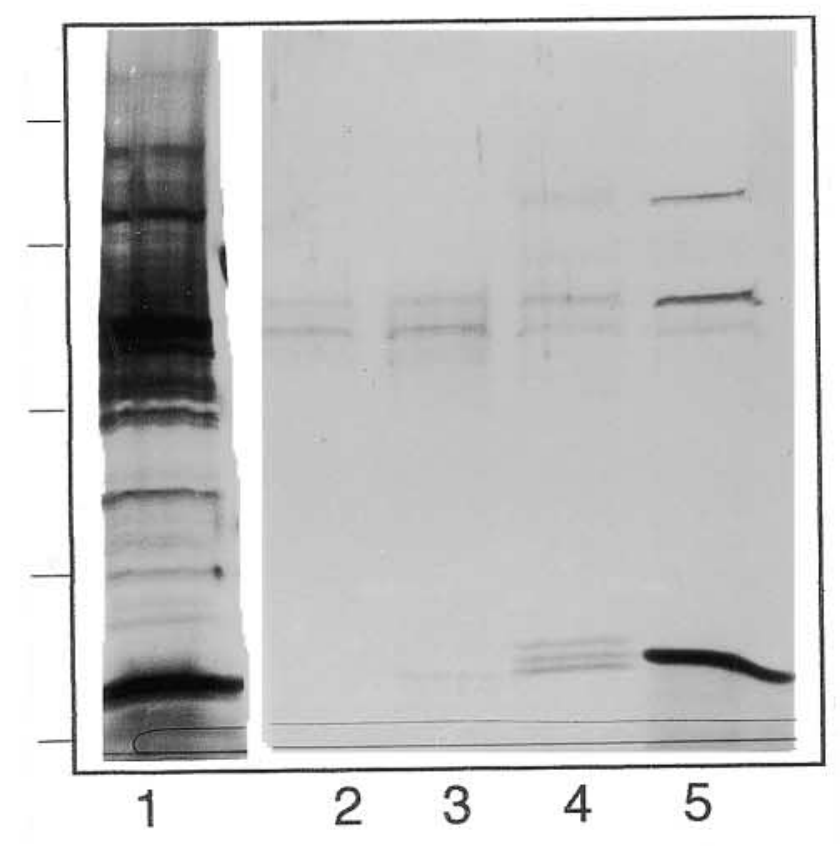

C

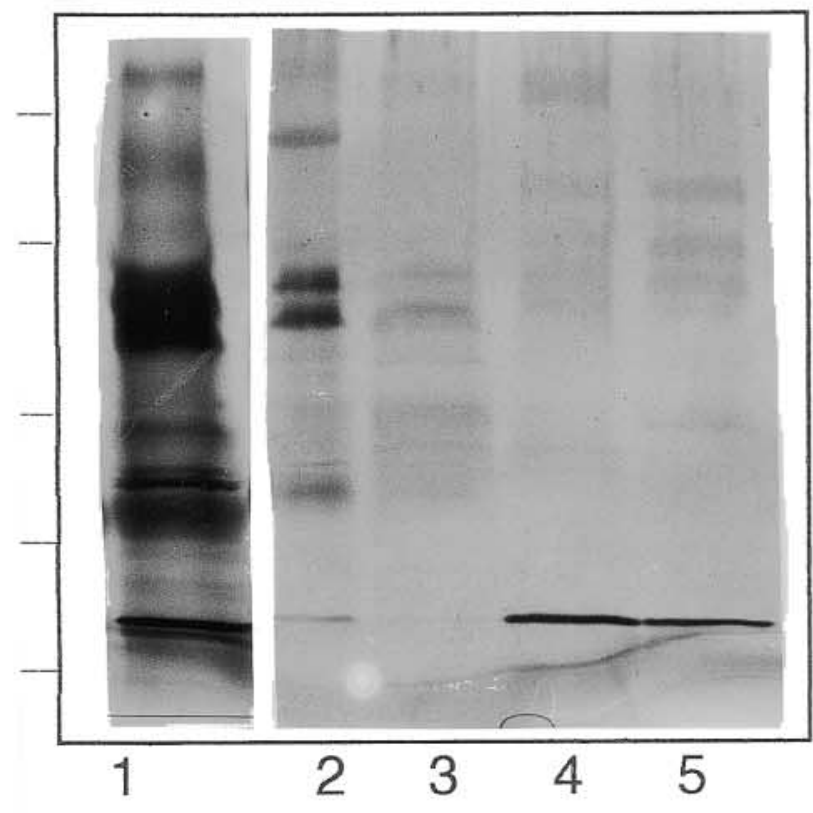

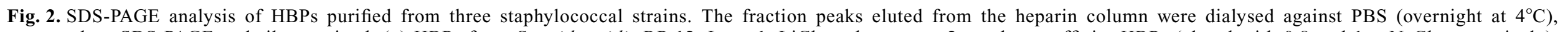

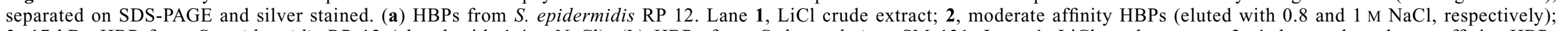

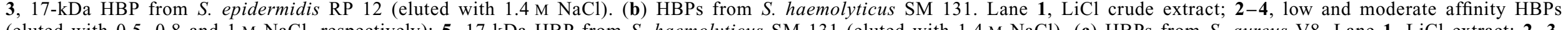
(eluted with $0.5,0.8$ and $1 \mathrm{M} \mathrm{NaCl}$, respectively); 5, 17-kDa HBP from $S$. haemolyticus SM 131 (eluted with $1.4 \mathrm{M} \mathrm{NaCl}$ ). (c) HBPs from $S$. aureus V8. Lane 1, LiCl extract, 2, low and moderate affinity HBPs (eluted with 0.5 and $0.8 \mathrm{M} \mathrm{NaCl}$ ) (the previously described 66- and 60-kDa proteins [7] were detected among these); 4, 5, 17-kDa HBP from $S$. aureus $\mathrm{V} 8$ (eluted with $1.4 \mathrm{M} \mathrm{NaCl}$ ). 
When membranes were probed with biotin-heparin or ${ }^{125}$ I-DTFA-heparin in PBS containing $1 \%$ BSA and Tween $200.1 \%, \mathrm{pH} 7.2$, only the major fraction with a size of c. $17 \mathrm{kDa}$ retained heparin-binding ability (Fig. $3 a$ and $b)$.

Inhibition assays [20] were perfomed by incubating the strips with biotinylated heparin combined with one of the inhibitors such as heparin, suramin, fucoidan and dextran sulphate $(100 \mu \mathrm{g} / \mathrm{ml}$ final concentration). The heparin binding to HBP was abolished by each of these inhibitors, but not by hyaluronic acid (Fig. 4a).

In SDS-PAGE experiments combined with immunoblot assays, the LiCl-extracted proteins from biotinylated staphylococcal cells included the same 17-kDa HBP as compared with the control, the non-biotinylated staphylococcal cells, thereby demonstrating the surface location of this protein (data not shown).

\section{bFGF immunoblot binding assay}

An earlier study demonstrated that CNS may bind bFGF and some other heparin-dependent growth factors [10], therefore the present study tested the possible binding of bFGF to HBP. As shown in Fig. 3a and b, lane 4, bFGF also bound to HBP isolated from $S$. epidermidis RP 12 and S. haemolyticus SM 131. The bFGF binding to HBP was almost completely abolished by heparin (Fig. 4b).

\section{Two-dimensional electrophoresis}

By 2-D electrophoresis combined with immunoblot, HBP was shown to be acidic with a pI c. 4.6 and a molecular mass of c. $17 \mathrm{kDa}$ (Fig. 5a and b).

\section{$N$-Terminal sequencing}

For the $17-\mathrm{kDa}$ proteins purified from S. epidermidis RP 12 and S. haemolyticus SM 131, the following sequences were obtained: MXTAHSYTXKYNGYTAN (GenBank accession no. tmpseq_AF1167348) and MATQTKGYYYSYNGYV (GenBank accession no. tmpseq_1AF169242), respectively. The N-terminal sequences of these two different staphylococcal species showed only limited identity, shown in bold. The sequences were compared in the EMBL Fasta Server Protein database; no homology with known staphylococcal cell-surface proteins or other microbial heparinbinding proteins was found. a

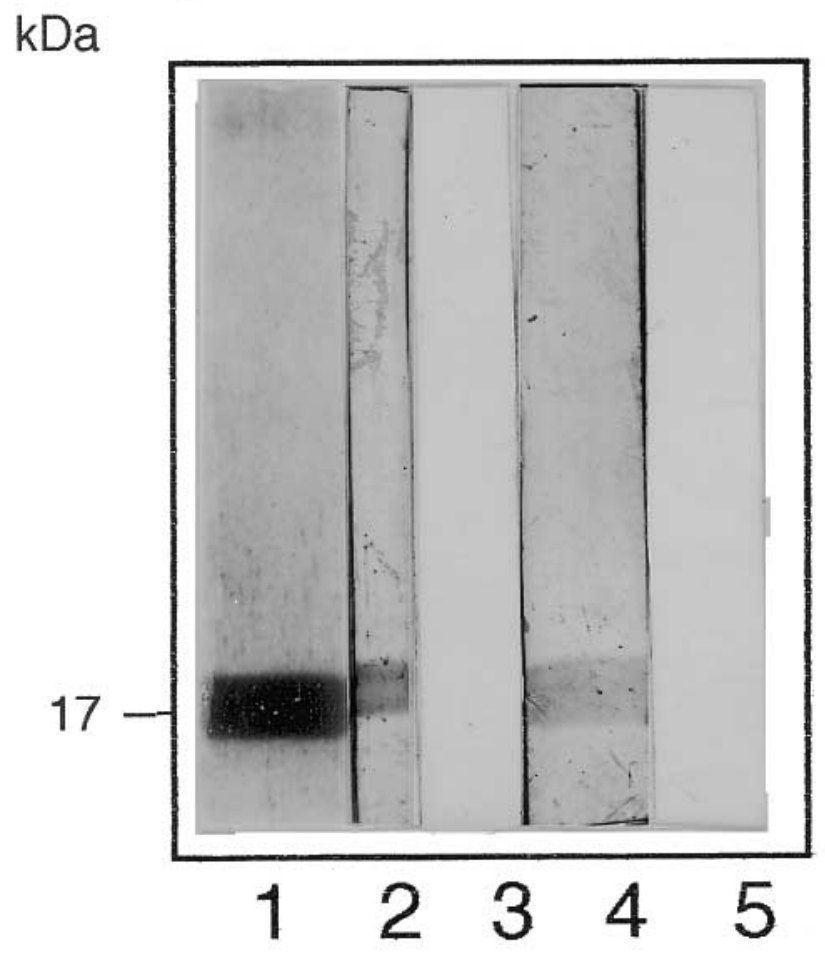

b

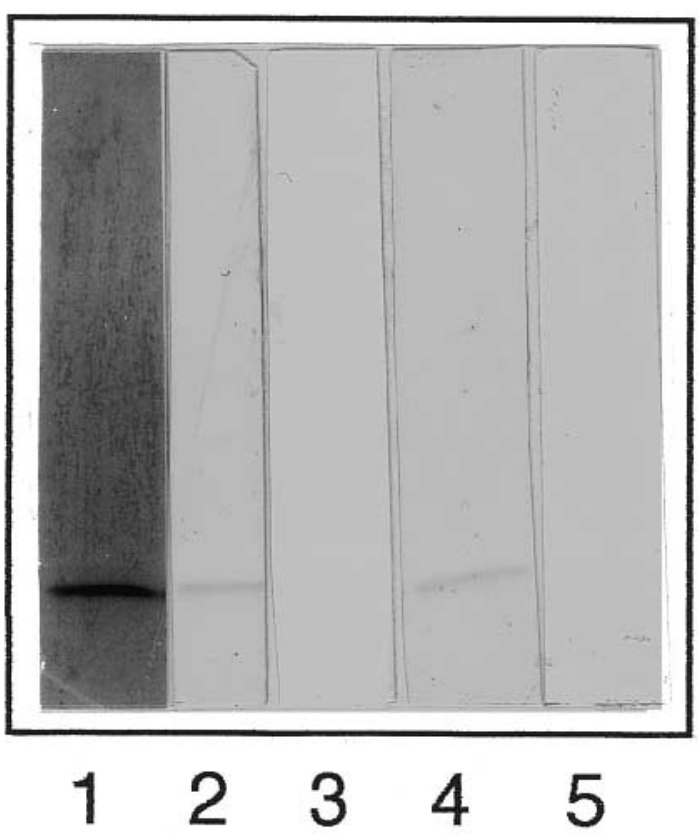

Fig. 3. Binding of heparin and bFGF to purified staphylococcal HBP. (a) HBP from S. epidermidis RP 12. (b) HBP from $S$. haemolyticus SM 131. The blots (a and b) were probed with ${ }^{125}$ I-DTAF-heparin (lane 1), biotinylated heparin (2) and bFGF (4). As controls, strips containing HBP incubated only with streptavidin-HRP (lane 3) or primary/ secondary antibodies (5), except biotinylated heparin and bFGF, respectively, were used. 
a

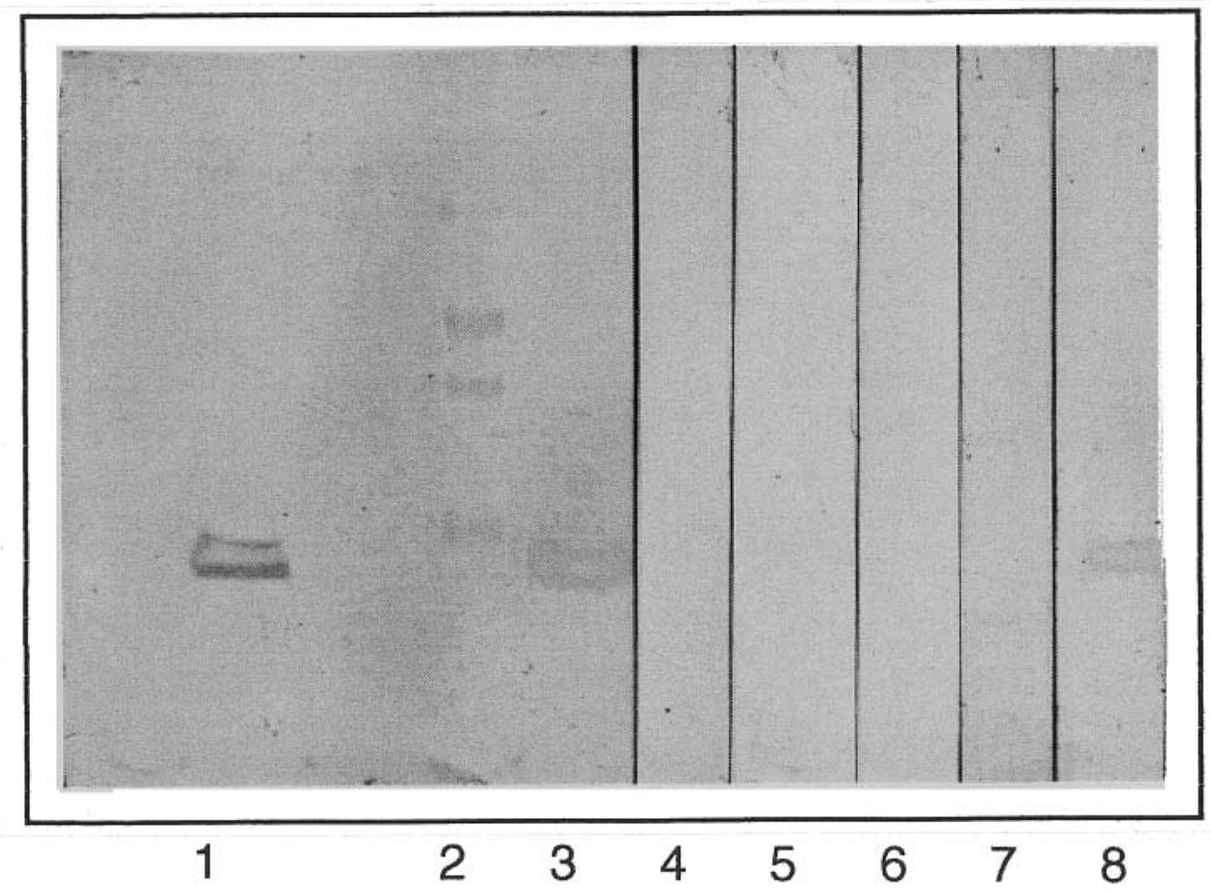

b

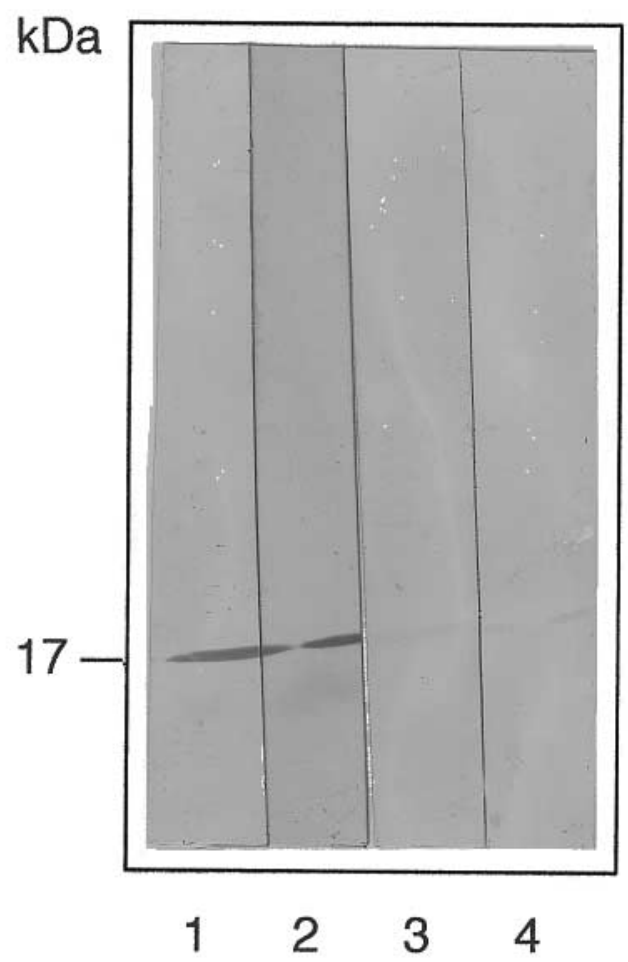

Fig. 4. Western blot competitive inhibition assays of (a) heparin and (b) bFGF binding to purified 17-kDa protein from $S$. epidermidis RP 12. The membranes were probed with biotinylated heparin (a) and bFGF/monoclonal antibody (b), respectively. (a) Lane 1, LiCl crude preparation; 2, molecular mass marker (20-103 kDa); 3, HBP probed with biotinylated heparin; 4-8, HBP incubated with a mixture of biotinylated heparin and one of the inhibitors $(100 \mu \mathrm{g} / \mathrm{ml}$ final concentration), i.e., heparin, fucoidan, dextran sulphate, pentosan polysulphate and hyaluronic acid, respectively. (b) Lane 1, HBP probed with biotinylated heparin; 2, HBP probed with bFGF/anti-bFGF antibody; 3, HBP preincubated with heparin $(100 \mu \mathrm{g} / \mathrm{ml}$ final concentration) before the strip was probed with $\mathrm{bFGF} / \mathrm{anti}-\mathrm{bFGF}$ antibody; 4, HBP incubated with a mixture of heparin and bFGF $(50 \mathrm{ng} / \mathrm{ml})$ before the strip was probed with monoclonal bFGF antibody. 


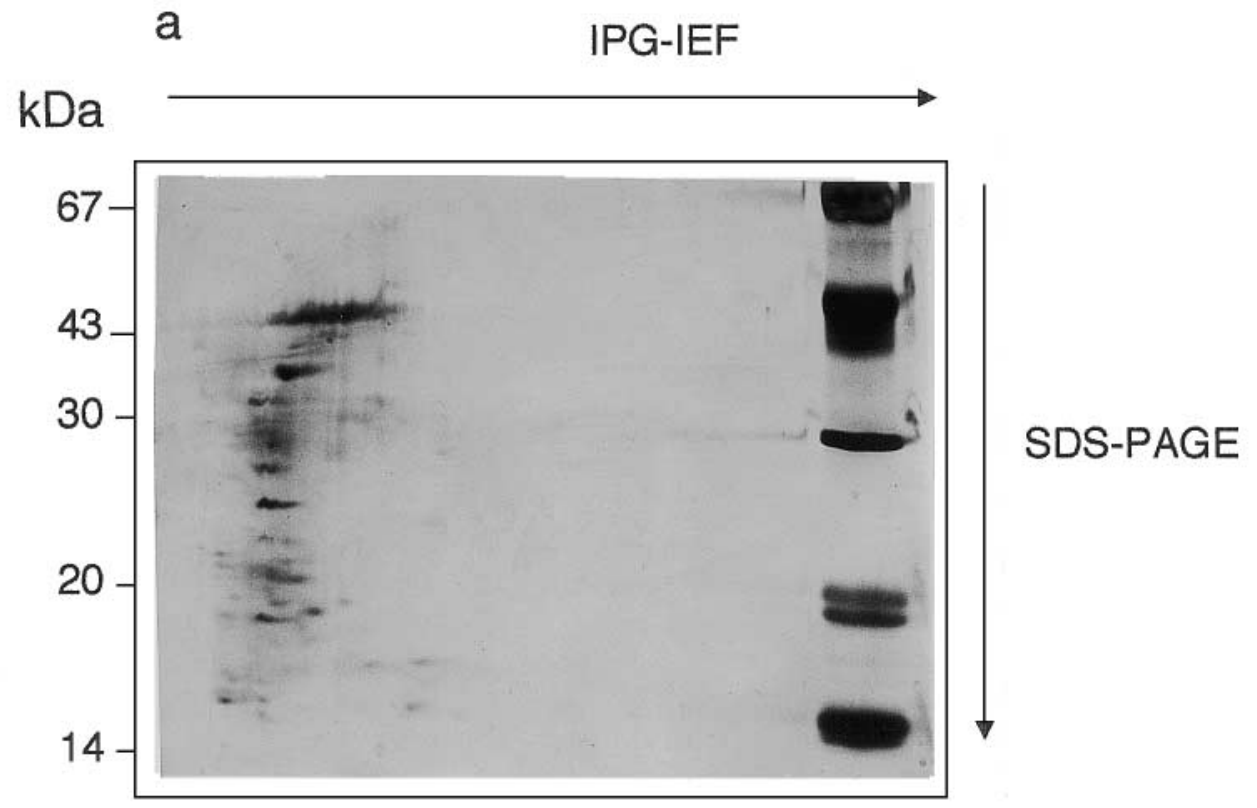

b

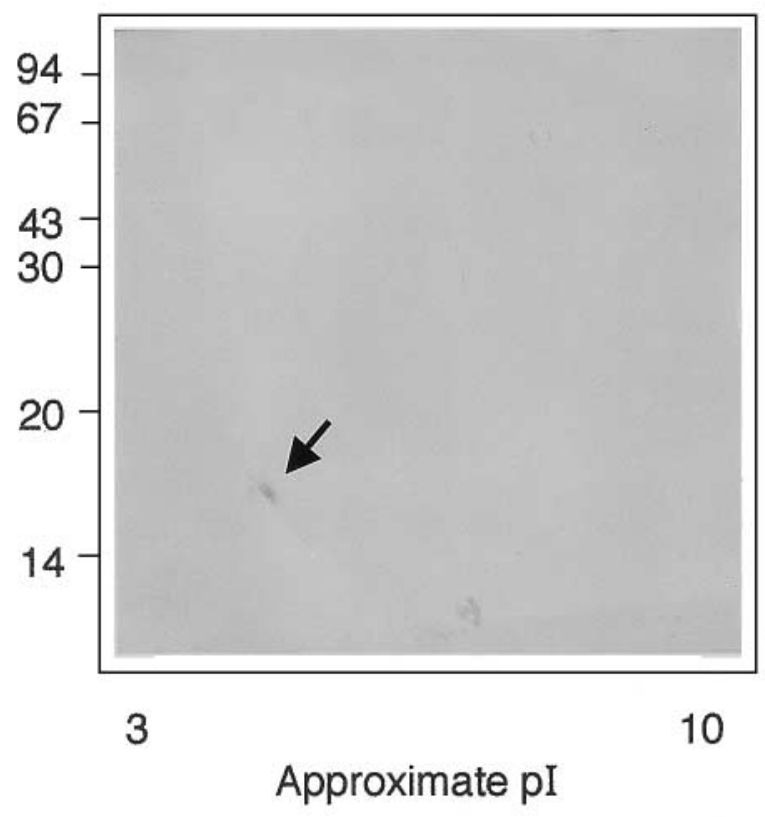

SDS-PAGE

Fig. 5. Two-dimensional gel electrophoresis of a $\mathrm{LiCl}$ extract of $S$. epidermidis RP 12 and Western blot after transfer to a PVDF membrane. The first dimension included iso-electric focusing in a pI range 3-10 and was followed by separation on an $8-18 \%$ gradient SDS-PAGE, and silver staining. The membrane was probed with biotinylated heparin. (a) Distribution of surface proteins, resolved by 2-D electrophoresis. (b) HBP, at $17 \mathrm{kDa}$ and a pI of 4.6, indicated by arrow.

\section{Binding of TSP and $v W F$ by HBP}

The broad specificity in the binding ability of HBP was investigated by a capture enzyme-linked immunosorbent assay (ELISA). As shown in Fig. 6, only TSP and to a lesser extent vWF (1.75-fold less than TSP) could be captured by HBP. Fg bound as well as HBP, but with a very weak affinity, as compared with the controls. Other serum and matrix proteins such as Fn and Vn did not bind HBP $\left(\mathrm{OD}_{450}\right.$ values similar to the background level).

\section{Discussion}

Many pathogenic micro-organisms use cell surface glycolipids and glycoproteins as receptor molecules for attachment or invasion, or both, of eukaryotic cells, as 


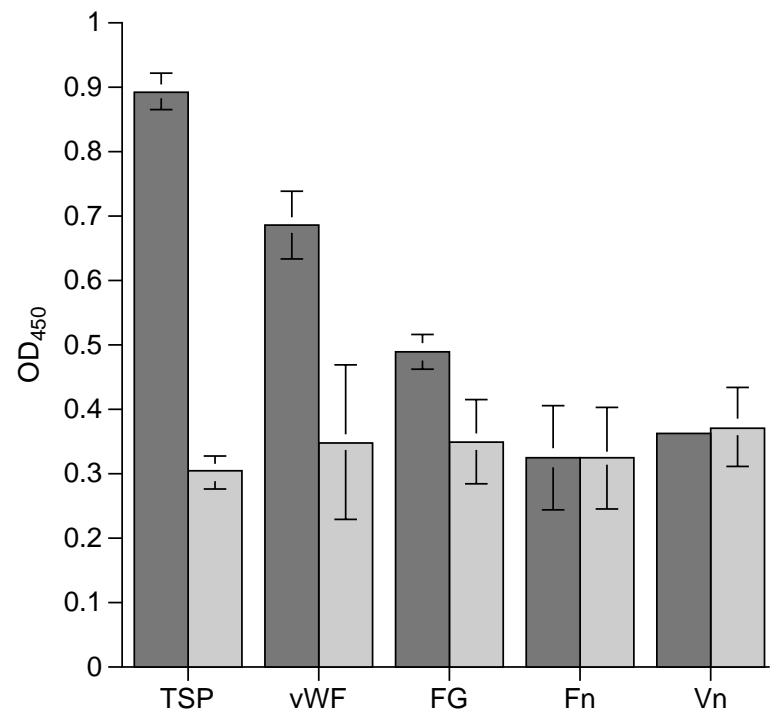

Fig. 6. Capture ELISA of TSP, vWF, Fg, Fn and Vn. Microtitration wells were coated with $100 \mu \mathrm{l}$ of a $5 \mu \mathrm{g} / \mathrm{ml}$ solution of $\operatorname{HBP}(S$. epidermidis RP 12). The TSP, vWF, Fg, Fn and Vn $(0.1 \mu \mathrm{g} / 100 \mu \mathrm{l})$ were added and binding was measured with HRP-conjugated antibodies against TSP, vWF, Fg, Fn and Vn (1 in 1000), respectively.

well as intercellular migration processes [21]. Various ECM proteins have been implicated in microbial binding, but interactions with GAGs have been poorly studied. Recently, it has become evident that many bacteria, parasites and viruses exploit GAGs as adhesion receptors [22] and that binding to ECM proteins and GAGs may also trigger various tissue reactions, such as thrombus formation and complement activation.

Previous studies have shown that $S$. aureus and $S$. epidermidis strains specifically interact with ECM molecules such as Fn, Vn, Cn, TSP, vWF, lactoferrin and transferrin, all of which contain heparin-binding domains [3-6, 23, 24]. For many of these interactions, not only heparin but also other polysulphated molecules, such as fucoidan, suramin and dextran sulphate, were potent inhibitors, whereas carboxylated or nonsulphated components were not inhibitory [25]. It has also been shown that staphylococci can interact with two heparin-dependent growth factors, bFGF and PDGF [10], which may affect tissue integration of implanted biomaterials. It is likely that these interactions can also stimulate other receptors on eukaryotic cells, which may involve secondary binding to bFGF receptors to trigger cell uptake and intracellular multiplication, as shown for gonococci [26].

For staphylococci, it might be of conceivable benefit to bind the different types of host cell GAGs through suitable adaptor molecules for different GAG motifs. The present study showed that staphylococci, in addition to heparin/HS, may bind other sulphated GAGs, such as chondroitin 4-sulphate and dextran sulphate (Fig. 1). The fact that staphylococci have the ability to bind to different sulphated polysaccharides with heterogeneous chemical structures may indicate that staphylococci express a promiscuous GAG receptor with variable affinity for different GAGs, which is consistent with other GAG-binding receptors [11].

The study aimed to examine the molecular mechanisms by which heparin/HS and bFGF interact with CNS strains, and a heparin-binding protein. Therefore, a HBP was purified from two different CNS strains by heparin affinity chromatography. The results suggest that HBP is a novel cell-surface protein, with a molecular mass of c. $17 \mathrm{kDa}$ and a pI of c. 4.6 (Fig. $5 b$ ), that has affinity for heparin, for the heparinbinding growth factor, bFGF (Fig. 3a and b), for TSP, for vWF and very weak affinity for Fg (Fig. 6).

A notable finding in the present study was that the Nterminal sequence of the HBP from $S$. haemolyticus SM 131 was almost completely identical to the sequence obtained in this laboratory for a TSP-binding protein $(c .16 \mathrm{kDa})$ isolated from the same strain $(\mathrm{M}$. Stollenwerk, unpublished observations). Furthermore, it was reported that binding to TSP and vWF by staphylococcal cells was totally blocked by heparin $[23,24]$, suggesting that the heparin-binding domains of these two molecules are involved in bacterial recognition.

Broad specificity binding proteins in $S$. aureus cells have been described previously [27]. By N-terminal analysis, the Vn-binding protein of $S$. aureus V8 showed identity with the HS-binding protein, indicating that the latter $60-\mathrm{kDa}$ surface protein mediates binding of $\mathrm{Vn}$ as well [28]. Interestingly, HBP from $S$. epidermidis RP 12 showed binding not only to bFGF, but to TSP, to vWF and very weakly to Fg. TSP and vWF are secreted from activated platelets during wound healing and have been proposed to mediate staphylococcal adhesion to biomaterial surfaces in the blood stream [23, 24, 29]. Recently, it was shown that $S$. aureus can activate platelets and promote their deposition on the ECM. Therefore, the secreted products may also bridge the deposition of $S$. aureus on to the subendothelium [30].

HBP is clearly distinct from the $20-\mathrm{kDa}$ sulphated polysaccharide purified from the extracellular slime layer of $S$. epidermidis [31], which behaves as a 30$\mathrm{kDa}$ band in SDS-PAGE and immunoblotting experiments on crude slime. Moreover, the HBP could not be detected in extracts prepared by sonication from $S$. epidermidis cells grown on tissue-culture dishes in TS (data not shown), as proposed for the isolation of a capsular polysaccharide/adhesin (PS/A, c. $28 \mathrm{kDa}$ ) [32]. As shown by the N-terminal sequence, S. epidermidis HBP is distinct from the previously reported 19-kDa Fg-binding protein of $S$. epidermidis, purified from culture supernates [33]. The relationship of HBP 
to other cell-surface components in $\mathrm{CNS}$ and its binding specificity merit further investigation.

As binding of heparin was common among CNS strains isolated from both patients and healthy carriers, any role of the expression of HBP for staphylococcal pathogenicity in man is unclear at present. As with binding of ECM molecules, including Fn, Vn, TSP and type IV Cn, GAG binding to staphylococcal cells may allow coating of these bacteria with host molecules, which may prevent attack by phagocytes and the immune system. Heparin binding by microbes was recently highlighted by Duensing et al. as a novel strategy in microbial pathogenesis that complements the classical virulence strategy [34]. This mechanism enables different bacterial species that bind heparin/HS and other GAGs to recruit structurally and functionally diverse bioactive host proteins, including adhesive glycoproteins (Fn and Vn), inflammatory and immunomodulatory mediators, and growth factors [34]. Adhesive proteins, such as Fn and Vn, have been implicated as intermediates in bacterial interactions with host cell integrin receptors, resulting in bacterial colonisation and invasion of epithelial cells [4]. From our ongoing studies, we also envisage a possible role for CNS heparin-binding abilities in the initial attachment of staphylococci to endothelial cells expressing both HS and TSP on their surface [35]. The interaction of staphylococci with GAGs may thus be important for efficient infection of eukaryotic cells by staphylococci. Furthermore, the binding of bFGF to staphylococcal cells might interfere with repair processes in the infected tissue.

In summary, the present study has demonstrated that staphylococci express surface components which recognise heparin-related polysaccharides, a heparindependent growth factor, bFGF, TSP and vWF. The biological importance of these interactions and their possible role in staphylococcal infections remain to be further investigated. The use and development of implanted artificial biomaterials is hampered by infectious complications. A better understanding of the pathogenesis of these infections might lead to interventions that directly attenuate bacterial virulence or modulate host responses, and ultimately to improved methods of bioimplantation.

This work was supported by grants from the Swedish Medical Research Council (B95-6X-11229), the Swedish Board for Technical Development (NUTEK), the Royal Physiographic Society of Lund and the Medical Faculty of the Lund University. We thank Professor O. Larm and I. Gouda from Medicarb AB, Bromma, Sweden for supplying the microtitration plates covalently coupled with heparin, chondroitin 4-sulphate and dextran sulphate, and to Dai-Qing Li for purifying human fibronectin and vitronectin.

\section{References}

1. Tsukayama DT. Management of prosthetic device infections. Rev Med Microbiol 1998; 9: 163-170.

2. Appelgren P, Ransjö L, Bindslev L, Larm O. Does surface heparinisation reduce bacterial colonisation of central venous catheters? Lancet 1995; 345: 130.

3. Ljungh $\AA$. Bacterial adhesion to extracellular matrix. Nova Acta Leopoldina NF 1997; 301: 27-41.

4. Ljungh A, Moran AP, Wadström T. Interactions of bacterial adhesins with extracellular matrix and plasma proteins: pathogenic implications and therapeutic possibilites. FEMS Immunol Med Microbiol 1996; 16: 117-126.

5. Paulsson M, Ljungh $\AA$, Wadström T. Rapid identification of fibronectin, vitronectin, laminin, and collagen cell surface binding proteins on coagulase-negative staphylococci by particle agglutination assays. $J$ Clin Microbiol 1992; 30: 2006-2012.

6. Ljungh $\AA$, Lundberg F. Bacterial adhesion to biomaterials. In: PI Harris, D Chapman (eds) New biomedical materials. IOS Press. 1998: 105-114.

7. Liang OD, Ascenscio F, Fransson L-Å, Wadström T. Binding of heparan sulfate to Staphylococcus aureus. Infect Immun 1992; 60: 899-906.

8. Yu J, Nordman Montelius M, Paulsson M et al. Adhesion of coagulase-negative staphylococci and adsorption of plasma proteins to heparinized polymer surfaces. Biomaterials 1994; 15: $805-814$.

9. Pascu C, Hirmo S, Ljungh Å, Wadström T. A particle agglutination assay for rapid identification of heparin binding to coagulase-negative staphylococci. J Med Microbiol 1996; 45: $263-269$.

10. Pascu C, Ljungh $\AA$, Wadström T. Staphylococci bind heparinbinding host growth factors. Curr Microbiol 1996; 32: 201-207.

11. Conrad HE. Heparin-binding proteins. San Diego, Academic Press. 1998.

12. Salmivirta $M$, Lidholt $K$, Lindahl U. Heparan sulfate: a piece of information. FASEB $J$ 1996; 10: 1270-1279.

13. Lindahl U, Lidholt K, Spillmann D, Kjellén L. More to "heparin" than anticoagulation. Thromb Res 1994; 75: 1-32.

14. Andriessen MP, van den Born J, Latijnhouwers MA, Berges M, van de Kerkhof PC, Shalkwijk J. Basal membrane heparan sulphate proteoglycan expression during wound healing in human skin. J Pathol 1997; 183: 264-271.

15. Stearns NA, Prigent-Richard S, Letourneur D, Castellot JJ. Synthesis and characterization of highly sensitive heparin probes for detection of heparin-binding proteins. Anal Biochem 1997; 247: 348-356.

16. Utt M, Wadström T. Identification of heparan sulphate binding surface proteins of Helicobacter pylori: inhibition of heparan sulphate binding with sulphated carbohydrate polymers. J Med Microbiol 1997; 46: 541-546.

17. Larm O, Adolfsson L, Gouda I, Malmberg A, Olsson P. An improved method for covalent immobilisation of heparin by endpoint attachment. Thromb Haemost 1987; 58: 84.

18. Nilsson I, Ljungh $\AA$, Aleljung P, Wadström T. Immunoblot assay for serodiagnosis of Helicobacter pylori infections. J Clin Microbiol 1997; 35: 427-432.

19. Spillmann D, Lindahl U. Glycosaminoglycan-protein interactions: a question of specificity. Curr Opin Struct Biol 1994; 4: $677-682$.

20. Keller JM. Specificity in heparin/heparan sulphate-protein interactions. Glycobiology 1994; 4: 1-2.

21. Wadström T, Ljungh A. Glycosaminoglycan-binding microbial proteins in tissue adhesion and invasion: key events in microbial pathogenicity. $J$ Med Microbiol 1999; 48: $223-233$.

22. Rostand KS, Esko JD. Microbial adherence and invasion through proteoglycans. Infect Immun 1997; 65: 1-8.

23. Herrmann M, Suchard SJ, Boxer LA, Waldvogel FA, Lew PD. Thrombospondin binds to Staphylococcus aureus and promotes staphylococcal adherence to surfaces. Infect Immun 1991; 59: 279-288.

24. Herrmann M, Hartleib J, Kehrel B, Montgomery RR, Sixma JJ, Peters G. Interaction of von Willebrand Factor with Staphylococcus aureus. J Infect Dis 1997; 176: 984-991.

25. Pascu C, Hirmo S, Ljungh $\AA$, Wadström T. Inhibition of extracellular matrix and serum protein binding to Staphylococcus aureus by heparin and various polysulphated agents. Med Microbiol Lett 1995; 4: 397-405.

26. Duensing TD, van Putten JPM. Vitronectin binds to the gonococcal adhesin OpaA through a glycosaminoglycan molecular bridge. Biochem $J$ 1998; 334: 133-139. 
27. McGavin MH, Krajewska-Pietrasik D, Rydén C, Höök M. Identification of a Staphylococcus aureus extracellular matrix binding protein with broad specificity. Infect Immun 1993; 61: 2479-2485.

28. Liang OD, Flock J-I, Wadström T. Evidence that the heparin-binding consensus sequence of vitronectin is recognized by Staphylococcus aureus. J Biochem 1994; 116: 457-463.

29. Yeaman MR. The role of platelets in antimicrobial host defenses. Clin Infect Dis 1997; 25: 951-970.

30. Shenkman B, Rubinstein E, Dardik R, Tamarin I, Savion N, Varon D. Activated platelets mediate Staphylococcus aureus deposition on subendothelial extracellular matrix: the role of glycoprotein Ib. Platelets 1999; 10: 36-44.

31. Arvaniti A, Karamanos NK, Dimitracopoulos G, Anastassiou ED. Isolation and characterization of a novel $20-\mathrm{kDa}$ sulphated polysaccharide from extracellular slime layer of
Staphylococcus epidermidis. Arch Biochem Biophys 1994; 2 : 432-438.

32. McKenney D, Hübner J, Muller E, Wang Y, Goldmann DA Pier GB. The ica locus of Staphylococcus epidermidis encodes production of the capsular/polysaccharide/adhesin. Infect Immun 1998; 66: 4711-4720.

33. Nilsson M, Frykberg L, Flock J-I, Pei L, Lindberg M, Guss B. A fibrinogen-binding protein of Staphylococcus epidermidis. Infect Immun 1998; 66: 2666-2673.

34. Duensing TD, Wing JS, van Putten JPM. Sulfated polysaccaride-directed recruitment of mammalian host proteins: a novel strategy in microbial pathogenesis. Infect Immun 1999; 67: $4463-4468$

35. Vischer P, Feitsma K, Schön P, Völker W. Perlecan is responsible for thrombospondin 1 binding on the cell surface of cultured porcine endothelial cells. Eur J Cell Biol 1997; 73: $332-343$. 